\title{
A MARCAÇÃO DE PLURAL NA LINGUAGEM INFANTIL - ESTUDO LONGITUDINAL
}

Elaine T. C. CAPELLARI

Ana M. S. ZILLES

Universidade Federal do Rio Grande do Sul

\section{RESUMO}

O presente artigo tem como objetivo explorar algumas questões referentes à marcação de plural na fala de uma criança. Para tal propósito, descreveremos e analisaremos o uso da concordância nominal na fala infantil em contraste com o que se considera regra variável de concordância característica da fala do adulto.

\section{ABSTRACT}

This article aims at examining some issues regarding the usage of plural forms in the speech of a child, with special attention to agreement phenomena. Noun agreement will be described and analysed as a variable rule, both in the speech of children and adult speakers.

\section{PALAVRAS-CHAVES}

concordância nominal, aquisição de concordância nominal, concordância variável, concordância no português do Brasil

\section{KEY WORDS}

Noun agreement, noun agreement acquisition, variable agreement, agreement in Braqilian Portuguese.

\section{Introdução}

$\mathrm{Na}$ primeira parte deste trabalho, serão descritos os elementos que compõem a morfologia do plural no português. A seguir, revisa- 
remos brevemente a literatura sobre a concordância nominal na fala do adulto, sob a perspectiva da Sociolingüística, especialmente Scherre (1996), discutindo algumas questões relacionadas com a descrição estrutural do SN e com o estatuto da categoria determinante. A seguir, abordaremos um trabalho sobre aquisição da morfologia de plural (Lamprecht, 1997). Na seção subseqüente, apresentaremos a análise de dados longitudinais da fala de uma criança de 4 a 8 anos de idade, extraídos do Banco de Dados do projeto Desenvolvimento da Linguagem da Criança em Fase de Letramento - DELICRI ${ }^{1}$, do Instituto de Letras da Universidade Federal do Rio Grande do Sul. Discutiremos, então, os elementos que favorecem a aplicação da regra de concordância padrão, ligados à estrutura do SN e ao papel do contexto discursivo. Finalmente, na última seção, apresentaremos algumas considerações sobre o papel da leitura e da escolarização na aquisição da concordância padrão de número na fala.

\section{A morfologia do plural na língua portuguesa}

A morfologia do plural do português padrão é bastante regular, constituindo-se, em grande parte, do acréscimo do morfema $-s$ no final dos vocábulos. São característicos, também, os alomorfes -es, -is para palavras que terminam em -r, -z, e -l, como em mar>mares; rapaz>rapazes; mal>males; animal>animais. Alguns substantivos paroxítonos terminados em -il substituem essa terminação por -eis, fóssil> fósseis. Para os nomes terminados em -ão, existem três possibilidades: 1) acréscimo do -s no fim da forma singular, mão $>$ mãos; 2) mudança de -ão para -ões, salão>salões; 3) mudança de -ão para -ães, pão>pães.

Concomitante a essas marcas de plural ocorre, em alguns casos, uma alteração na estrutura fonológica da palavra, do tipo: ovo >óvos ${ }^{2}$; gostoso>gostósos. Conforme Camara (1976:78), essa alternância teve origem no latim. As vogais breves existentes no latim clássico passaram para o latim vulgar com um timbre aberto. Entretanto, alguns nomes com vogal breve $\hat{o}$ mantiveram essa vogal fechada, devido à 
metafonia. Esse fenômeno é um processo de assimilação de traços de uma vogal por outra. Tem-se como exemplo a palavra grossu (acusativo, masculino, singular), que conservou o timbre fechado devido à vogal final $u$, resultando em grôsso. Já na forma plural gróssos não houve metafonia, passando o $\hat{o}$ breve para ó, de acordo com o que ocorreu com as outras vogais breves, que também se tornaram abertas. Esse traço passou a ser, desde então, uma característica redundante da marcação do plural. De acordo com o que será abordado na próxima seção, palavras que apresentam essa alternância na estrutura fonológica têm uma maior probabilidade de aplicação da regra de marcação do plural. Por fim, temos ainda expressões invariáveis como o pessoal, que são semanticamente plurais.

\section{A marcação do plural na fala dos adultos}

A língua padrão estabelece como regra geral que os elementos flexionáveis de um SN devem concordar em gênero e número com o núcleo desse sintagma, que é, normalmente, um substantivo ou palavra com valor de substantivo. Essa regra, usada principalmente na escrita, constitui a variante de maior prestígio, e o que se distancia dela é, em princípio, estigmatizado. Entretanto, trabalhos que se voltam para a língua falada evidenciam que a marcação de plural na fala é variável. Do que se observa, a tendência que mais se sobressai é a de marcar formalmente o plural apenas no primeiro elemento do sintagma. Nesta seção, discutimos alguns trabalhos que descrevem a concordância nominal na fala.

O primeiro deles analisa as variáveis que influenciam o português falado na cidade do Rio de Janeiro (Scherre, 1996), segundo a perspectiva da Sociolingüística Variacionista Laboviana.

De acordo com os dados analisados por Scherre (1996:88), na fala há diversas possibilidades de se marcar o plural nos SNs: a) plural em todos os elementos do SN (que é a forma padrão); b) em alguns elementos do SN; c) em apenas um elemento; d) nenhuma marca formal de plural. 
$\mathrm{Na}$ discussão dos resultados, três pontos são destacados por Scherre. A primeira constatação diz respeito ao que já havia sido referido, na seção anterior deste artigo, com relação às palavras com plural metafônico. Estas são mais propensas à marcação formal de plural, devido ao que Scherre (1996:89) chama de saliência fônica, isto é, palavras que apresentam alguma mudança na estrutura fonológica, quando pluralizadas, são mais perceptíveis foneticamente e, por isso, mais marcadas ${ }^{3}$. A segunda constatação referese ao item d) acima: SNs que possuem algum elemento com carga semântica de plural apresentam-se, na maioria das vezes, sem flexão de número. A terceira mostra que itens lexicais diminutivos e aqueles tipicamente informais desfavorecem a pluralização (casinha $\varnothing$, bobeira $\varnothing)$. Após essas observações, Scherre (1996:91) passa à análise das seguintes variáveis lingüísticas: 1) relação entre elementos nucleares/não nucleares e posição linear dos elementos no SN e 2) marcas precedentes em função da posição.

No primeiro cruzamento, segundo Scherre (1996:99), as classes gramaticais foram organizadas em dois grandes grupos, chamados de nucleares (substantivo, categoria substantivada e pronome pessoal de terceira pessoa) e não nucleares (adjetivo, quantificador, possessivo, artigo, demonstrativo, pronome indefinido e identificador). Com essa análise, a autora concluiu que classes não nucleares antepostas ao núcleo do $\mathrm{SN}$ recebem mais marcas de plural do que as pospostas.

Com relação aos elementos nucleares, marcam-se mais os de primeira e terceira posições, sendo menos favorecida a segunda. De acordo com essas constatações, Scherre estabelece duas possibilidades: a primeira, prevê a influência da coesão sintagmática como hipótese determinante para a marcação ou não de plural. Segundo Scherre (1996:100), quanto mais coesão, mais marcas; quanto menos coesão, menos marcas. A segunda possibilidade sugere uma generalização para o fato de ser a posição de determinante a mais marcada no SN; basicamente, seriam os constituintes do lado esquerdo os mais favorecidos para as 
marcas formais de plural. Com relação à segunda posição, esta seria menos marcada por ser um lugar de pouca coesão no sintagma, pois é nessa posição que se inserem elementos, modificadores ou não, no SN. A não marcação formal é vista como um índice de que não há uma ligação estreita entre estes elementos; portanto, nessa posição, não há uma forte coesão sintagmática. Seguindo o mesmo raciocínio, a autora acrescenta que a aplicação do morfema $-s$ nos constituintes reforça a coesão existente entre eles.

No segundo cruzamento, marcas precedentes em função da posição, foram estabelecidos nove fatores. De acordo com os resultados obtidos, Scherre (1996:105) chega a uma explicação genérica que retoma o que Poplack já havia constatado no espanhol: a presença de uma marca de plural antes do dado favorece a retenção da marca naquele dado, enquanto que a ausência de uma marca precedente favorece o cancelamento. Assim, se o núcleo semântico for formalmente marcado, ou seguido de marca formal, o segmento seguinte será muito provavelmente marcado e vice-versa.

A segunda parte da análise de Scherre (1996:239) trata das variáveis escolarização, sexo, idade e mercado ocupacional, considerando os mesmos falantes. Sintetizamos os resultados das análises já considerando os cruzamentos entre as variáveis selecionadas. A presença de concordância nominal é proporcional aos anos de escolarização. Contudo, essa variável influencia mais o sexo feminino que o masculino, que tem como influência maior o mercado de trabalho, principalmente na faixa etária de 15 a 25 anos. A idade mostrou-se uma variável de pouca influência para ambos os sexos. Entretanto, é curioso observar as faixas etárias em que se evidencia maior uso da concordância nominal: para as mulheres, 26 a 49 anos, e para os homens, 15 a 25 anos. A variável sexo aponta para um uso mais acentuado da concordância nominal entre as mulheres. O mercado de trabalho influencia ambos os sexos, mas torna-se mais determinante nos homens, ao passo que, para as mulheres, o que mais influencia são os anos de escolarização. 
Parece-nos importante discutir alguns aspectos da análise proposta por Scherre, especialmente quanto às variáveis lingüísticas. Nossas considerações referem-se à classificação nuclear e não-nuclear que Scherre atribui às classes gramaticais. Cogitamos a hipótese de que certas categorias, tais como numerais e quantificadores, mereçam um tratamento à parte. Gostaríamos, também, de discutir a noção de determinante, bem como a concepção apenas linear da estrutura do sintagma nominal. Talvez seja mais adequado adotar uma concepção hierárquica para a constituição interna do SN.

\section{A estrutura interna do SN: algumas questões}

Nesta seção, apresentaremos alguns trabalhos que questionam uma concepção linear da estrutura do SN tal como a proposta por Scherre (1996). No primeiro deles, Pontes (1978) traz a descrição do quantificador todos, pondo em destaque seu comportamento sintático diferente. Segundo a autora, o único det que pode preceder pronomes é todos $\rightarrow$ todos nós. Ou seja, nenhum outro det pode acompanhar pronomes:

*Os eles chegaram./ Todos eles chegaram.

Pontes (1978:152) ainda afirma que todos pode se movimentar para depois do SN, para depois do verbo e até para o fim da oração.

a. Os meninos todos foram à festa.

b. Os meninos foram todos à festa.

c. Os meninos foram à festa, todos.

Outro estudo muito conhecido sobre a estrutura do SN é o de Koch (1983:16-18). Conforme a autora, a estrutura do SN é composta de determinante + nome. Todavia, o determinante pode ser simples ou complexo; quando simples, é representado por um artigo, 
numeral ou pronome adjetivo. Quando complexo, o determinante compõe-se de mais de um elemento: o determinante base (det-base), que é representado pelo artigo ou pelo demonstrativo (todos os alunos, estes dois meninos); não havendo nem artigo nem demonstrativo, um possessivo pode ocupar a posição de det-base (nossos bons companheiros); funcionam como pós-determinantes os numerais e os possessivos (estes meus cinco amigos) e como pré-determinantes os quantificadores e expressões partitivas (todos os meus amigos, alguns dos meus amigos). Assim sendo, a estrutura completa do determinante é a seguinte:

$$
\text { Det } \rightarrow \text { (pré-det) det-base (pós-det) }
$$

Essa proposta apresentada por Koch nos sugere uma hierarquia na estrutura do determinante e talvez isso possa ter alguma relação com a marcação de plural, haja vista serem essas as posições iniciais, ou pré-nucleares, do SN.

Em trabalho mais recente, Perini (1998) toma por base a liberdade de movimentação que o elemento todos apresenta para classificá-lo como predeterminante, como um termo que não pertence à estrutura do SN (1998:108). O autor ainda reforça o seu ponto de vista, apresentando uma frase na qual todos aparece depois do sintagma nominal.

Os crocodilos todos gostam de frango.

Com essa frase o autor afirma (1998:109) que muitos falantes, embora aceitem essa frase como bem formada, "sentem" que os crocodilos todos não forma um constituinte - o que pode ser tomado como uma indicação a mais de que todos não pertence ao SN.

Note-se, ademais, que seria possível dizer também

Os crocodilos gostam todos de frango. 
Um outro aspecto que vale considerar, a respeito da estrutura sintática do SN vem do registro de certas ocorrências históricas, feito por Rosa Virgínia Mattos e Silva em Estruturas Trecentistas - Elementos para uma gramática do português arcaico (1989). Nesse trabalho, a autora analisa textos de português arcaico e descreve o comportamento dos alomorfes lo, los, la, las. Estes alomorfes se combinavam com certos morfemas gramaticais independentes: após, depós, despós, ambas, todos, todas, per, constituindo um único vocábulo fonético apolos, apolas, depola, depolos, ambalas, todolos, todolas, pelo, pela, pelos, pelas. Tal variação decorre de um processo fonético assimilatório em que as consoantes finais $-s$, $-r$ dos morfemas independentes adquirem os traços da consoante que as segue.

É de nosso interesse destacar a discrepância na freqüência de ocorrências entre as formas todolos/-las e todos os/as. A autora registra 177 ocorrências para a forma combinada todolos/-las e apenas 5, para todos os/as. Desse levantamento, ela conclui que as formas combinadas em desuso hoje no português padrão, pelo menos eram as preferenciais no corpus analisado.

De nossa parte, queremos, sobretudo, associar esse registro histórico ao que se observa com o operador todos. Queremos, portanto, supor que as formas combinadas não estão tão em desuso hoje, revendo, em parte, o que afirma Mattos e Silva. Para tal suposição, propomos que esse operador tenha tido o seguinte percurso diacrônico:

todolos $>$ todoos $>$ tod'os

Nesse percurso, o operador todos perde o $-s$ por assimilação de traços de los; a seguir, com a queda do /1/, cria-se contexto para que ocorra a crase (fusão de vogais idênticas). Note-se que, segundo Pontes (1978:153), os quantificadores no plural não podem prescindir de artigo definido ou demonstrativos, pelo menos na língua padrão, o que se evidencia nos exemplos a seguir. 
*Todos meninos saíram./ Todos os meninos saíram.

Nesse contexto (todos os), poderia ocorrer também a junção do artigo sem a perda do $-s$ de todos, ocasionando todosos meninos. Entretanto, parece que não se observa, de modo geral, na fala cotidiana, a presença dessa sílaba, talvez pouco provável por formar palavra proparoxítona, avessa à tendência maior da língua. Ficamos, então, com a hipótese de assimilação e crase do artigo com o operador, com a perda do $-s$ e da vogal deste último.

Tod'os meninos saíram.

Haveria, pois, além da diferença no comportamento sintático de todos, uma explicação fonética histórica para não ${ }^{4}$ apresentar, na superfície, a marca de plural, dada a assimilação e a fusão com o artigo a ele posposto. Assim, supomos que sua inclusão na categoria dos elementos não-nucleares mais oblitera do que revela o funcionamento da regra variável de concordância nominal.

Com base nos estudos referidos, pensamos que enquadrar todos na estrutura do SN e incluí-lo na categoria de termos não nucleares, como fez Scherre, juntamente com outras classes com comportamento sintático diferente, parece ser uma análise questionável. Da mesma forma, enquadrá-lo como determinante talvez não seja o mais adequado, pois essa proposta parece-nos muito redutora. Pensamos, também, que os critérios usados para separar as classes gramaticais em duas categorias apenas, nuclear e não-nuclear, talvez não sejam satisfatórios.

Com isso, salientamos que nosso questionamento se volta para a estrutura do SN (determinante + nome), pois de acordo com o que vimos sobre o item todos, por exemplo, ele pode ser rotulado como determinante e, ao mesmo tempo, apresentar muitas características que o distinguem dessa classe. Há também a possibilidade de ser o próprio determinante, conforme Koch e Perini, uma estrutura com- 
plexa, nos instigando, assim, a refletir sobre a hipótese de haver uma explicação categorial para a marcação variável de plural no português falado do Brasil.

Portanto, essas considerações suscitam a idéia de que a marcação de número plural na fala depende de outros fatores estruturais que não se reduzem a ser ou não ser núcleo, nem a estar antes ou depois dele.

\section{O plural na fala das crianças}

De acordo com o que já foi visto até o momento, podemos observar que vários são os trabalhos sobre a concordância de número na fala dos adultos. Porém no que se refere à fala das crianças, infelizmente, não dispomos de muitos trabalhos na área. Nesta seção, apresentaremos os resultados de um estudo de Regina Lamprecht (1997), sobre a aquisição da morfologia do plural por crianças bilíngües alemão-português em comparação com crianças monolíngües falantes quer de alemão, quer de português.

Lamprecht (1997:107) volta-se para a aquisição dos sistemas de alomorfes do plural dessas duas línguas (1997:107), comparando as regularidades e obrigatoriedades existentes entre elas.

A pesquisadora, comparando os dois sistemas, observa que o português e o alemão têm em comum os alomorfes zero e $-s$ e a possibilidade de Umlaut 5 com este último. Acrescenta, ainda, que a morfologia do plural do português é simples, mas a marcação formal do plural é uma regra variável que depende de vários fatores extralingüísticos, ao contrário do alemão, que apresenta uma morfologia complexa e irregular, mas que se aplica como regra categórica. Portanto, cada língua apresenta dificuldades diferentes ao aprendiz

Para comparar a aquisição da morfologia do plural do português entre crianças bilíngües de português-alemão e monolíngües falantes de português, a autora coletou dados principalmente em Jardins de Infância. Ao todo foram 48 crianças entre 2;3 e 5;6 anos, divididas em 6 faixas etárias $(\mathrm{F} 1=2 ; 3$ a 3;0 / F2 = 3;0 a 3;6 / F3 = 3;6 a 4;0 / $\mathrm{F} 4=4 ; 0$ a $4 ; 6 / \mathrm{F} 5=4 ; 6$ a $5 ; 0 / \mathrm{F} 6=5 ; 0$ a $5 ; 6)$. 
As crianças foram entrevistadas em seu ambiente pré-escolar; poucas foram vistas em casa. Os dados provêm de fala elicitada, baseados em uma lista de palavras apropriadas para o léxico infantil. Com a ajuda de brinquedos, desenhos e objetos, puderam-se elicitar os contextos de plural em português na fala das crianças. As entrevistas foram gravadas em fitas cassetes, resultando em um total de 2.639 contextos de plural, aproximadamente 55 por sujeito.

O levantamento dos dados mostrou baixas porcentagens de marcação do plural em todas as faixas etárias. A maior freqüência, tanto de marcação padrão quanto incorreta, chegou a $14 \%$ na faixa dos 5;0 aos 5;6. Entretanto, Lamprecht afirma que quando se trata de marcar o plural por alomorfes, as crianças demonstram um alto índice de "acertos", sobretudo, grande adequação de uso em comparação com o registro informal dos adultos (que a autora não chega a caracterizar). Nesse sentido, as formas incorretas encontradas nos dados das crianças, em relação ao sistema morfológico, equivalem a apenas 2,6\% (69 dos 2.639 contextos analisados). Sobre isso, Lamprecht (1997:110), afirma que:

\section{Devido ao input a que estão expostas, as crianças parecem acreditar que não é necessária a marcação do plural quando este fica claro no determinante ou por meio de um numeral. Em resumo, as crianças conhecem o sistema mas parecem não saber que a marcação é "desejável".}

A autora, de acordo com seus dados, classifica em dois tipos os "erros" encontrados em relação à morfologia do plural do português. O primeiro tipo é em relação ao plural marcado com $-s$, mais alteração na estrutura fonológica (plural metafônico); o segundo, às supergeneralizações.

O primeiro grupo refere-se à marcação redundante de plural, ou seja, ao plural metafônico. Foi o tipo de ocorrência que mais aconteceu. Observou-se que as crianças lidam com essas palavras de duas maneiras: 
a. inserção de $-s$, mas sem alteração da estrutura fonológica da palavra:

ôlhos em vez de ólhos

pôrcos em vez de pórcos

ôvos em vez de óvos

b. ausência de -s final, mas com alteração da estrutura fonológica ólho em vez de ólhos

O segundo grupo refere-se às supergeneralizações:

a. supergeneralização de $-s$

sols em vez de sóis

caminhãos em vez de caminhões

flors em vez de flores

b. supergeneralização de is

chapéis em vez de chapéus

No que diz respeito ao input, a autora sustenta que sua influência mostrou-se evidente em sua pesquisa. Lamprecht destaca o desempenho de duas crianças, designadas por ela como marcadoras, e constata que essas crianças provêm de famílias em que a linguagem usada é muito próxima da norma culta ${ }^{7}$. A autora obteve como resultado para uma dessas crianças, na faixa dos 3;11, um total de marcação de $42 \%$, enquanto que a média para a sua idade é de $7 \%$. A outra criança, na idade de 4;5 apresenta um índice de 67\% para uma média de $9 \%$ em sua faixa etária. Deste modo, a autora reforça o papel do input para as crianças na aquisição da morfologia do plural do português.

Nos dados dos sujeitos monolíngües brasileiros, Lamprecht observa uma curva em "U”. As crianças, na faixa dos 4;6 -5;0, apresentam uma queda de desempenho no que tange à marcação "correta" dos 
alomorfes e nos plurais metafônicos. A autora argumenta que tal comportamento se dá devido ao aumento da consciência metalingüística nessa faixa etária e ainda afirma que talvez a criança comece a enxergar com mais clareza a regra que torna opcional a marcação de plural. $\mathrm{O}$ interessante é que, como veremos, nossos dados também são escassos nessa fase. Talvez possamos atribuir isso às mesmas razões apresentadas por Lamprecht.

Os dados de crianças bilíngües, tendo o alemão como segunda língua, foram coletados de uma pesquisa com 11 sujeitos nessa situação. O corpus constitui-se de 5 meninos e 6 meninas entre 3;0 e 5;7 anos. Estes sujeitos distribuem-se em três faixas etárias (FE $1=2$ crianças com média de idade de 3;5 / FE 2= 3 crianças com média de idade de 4;5 / FE 3= 6 crianças com média de idade de 5;5).

Essas crianças têm como input o português falado no RS e o alemão padrão (Hochdeutsch). As entrevistas foram feitas na casa das crianças. Com a ajuda de brinquedos, livros e desenhos, as crianças produziam os dados em contextos de plural. Obteve-se como resultado um total de 595 contextos de plural em português - média de 54 por sujeito - e de 661 em alemão - média de 60 contextos por sujeito.

Depois de caracterizar os dois grupos, a autora estabelece a primeira comparação entre as crianças bilíngües e monolíngües falantes de alemão ${ }^{8}$ em relação ao sistema do plural dessa língua. Por um lado, as crianças bilíngües apresentam um desempenho menor em relação às monolíngües falantes de alemão, no que diz respeito ao uso "correto" da morfologia do plural do alemão. Por outro lado, as bilíngües, quando comparadas às monolíngües em português, apresentam um número maior de "acertos" para a morfologia do plural do português. A comparação entre os dois grupos analisados, entretanto, mostrou que ambos apresentavam as mesmas dificuldades em relação à morfologia do português.

Diante desses resultados, Lamprecht (1997:115) estabelece as seguintes conclusões. A primeira, reforça o papel do input. As crianças bilíngües não dominam o sistema de regras do plural do alemão 
porque estão menos expostas a esse sistema, já que é a sua segunda língua. $\mathrm{O}$ mesmo vale para as monolíngües em português. As que estão expostas a uma variante mais culta apresentam um uso mais intenso das regras de marcação de plural na fala. A segunda conclusão vai no sentido de explicar por que as crianças bilíngües fazem mais plural padrão em português do que as monolíngües. Segundo Lamprecht (1997:116), as crianças bilingües parecem prestar mais atenção ao final das palavras do que as monolingües falantes de português porque em alemão essa atenção é vital. Isto é, no alemão o final das palavras é muito importante não só para a marcação do plural, mas também, para as declinações de caso, cujo padrão mais freqüente é PALAVRA=RAIZ+SUFIXO. Já as crianças brasileiras não se deparam com essa estrutura uma vez que, em português, não há marca de caso, e a regra de marcação de plural é variável, regida por regras sintáticas relacionadas com a posição no SN, entre outros fatores, tornando o uso do sufixo opcional.

Em contraste com o que Scherre estabelece para os plurais metafônicos, podemos perceber que, se esse é um fator que favorece a marca de plural na fala dos adultos, para as crianças esses itens apresentam muitas dificuldades. Mesmo assim, supomos que a retenção da marca de número na fala dos adultos, nos plurais metafônicos, se deve a um processo de memorização e de inferência de regras ocorrido na infância.

A relação que o trabalho de Lamprecht tem com o nosso vai no sentido de compararmos alguns aspectos levantados pela autora com o que encontramos nos dados de uma criança entrevistada no período dos 4 aos 8 , cuja fala estudamos.

\section{Metodologia}

Os dados analisados neste trabalho provêm de uma coleta longitudinal e pertencem ao Banco de Dados do projeto Desenvolvimento da Linguagem da Criança em Fase de Letramento - DELICRI. Essa coleta foi realizada durante o período de 1992 a 1996 em uma 
escola particular de Porto Alegre, chamada Escola Projeto. As informações aqui apresentadas sobre o projeto e a sua metodologia foram retiradas do relatório de 1995 do projeto DELICRI, coordenado, na época, pela professora Ana Maria de Mattos Guimarães, e, atualmente, pela professora Luciene Juliano Simões.

A criança cujos dados são analisados chama-se Carmela. São ao todo dezoito entrevistas, sendo que a primeira foi aos 4;03 e a última, aos 8;05.019 ; cada entrevista tem, em média, dez minutos. Carmela não tinha irmãos naquele período, sempre estudou na Escola Projeto e, conforme o relatório, não tinha nenhum contato com língua estrangeira. Seu pai, na ocasião, era fotógrafo e sua mãe, relações públicas; a escolaridade deles não foi informada. A categoria socioeconômica em que se enquadram é a B. Para tal categorização, o projeto estipulou alguns critérios, a saber:

Classe A: nivel superior - escolaridade superior de pelo menos um dos pais; profissão liberal, professores de $3^{\circ}$ grau, empresários, dirigentes; bairro de moradia considerado $A$ na cidade; escola particular.

Classe B: nivel médio - escolaridade de $1^{\circ}$ grau completo ou $2^{\circ}$ grau; funcionário público, comerciante, técnico, bancário, escriturário, professor de escola secundária ou primária; bairro de moradia considerado de classe média; escola pública.

Classe $C$ : nível baixo - pais com $1^{\circ}$ grau incompleto ou sem escolaridade; empregado doméstico, pedreiro, faxineiro, motorista, serviços gerais; bairro considerado "pobre"; escola pública.

Cabe lembrar que, pela idade inicial de Carmela (4 anos), não se está investigando a emergência da marcação de plural, que acontece aos 2 anos. O que se está investigando é em que medida a fala da criança é comparável à do adulto e, indiretamente, o que acontece na fase de alfabetização - quando a criança é exposta à língua padrão na escola. 
Os dados de Carmela encontram-se transcritos e digitados no Banco de Dados do projeto DELICRI e foram impressos para que se procedesse ao levantamento dos SNs plurais, padrão ou não, considerando-se o contexto em que foram produzidos. Entendese por contexto o seguinte: em cada entrevista, há momentos em que a criança faz um relato pessoal, em outros, conta uma historinha para a entrevistadora e há, às vezes, uma parte em que ela tem que elaborar uma narrativa baseada em figuras que lhe são mostradas. Portanto, consideramos dois contextos: relato pessoal, em que se espera maior grau de informalidade na linguagem, e narrativa oral de historinha, em que se espera linguagem mais formal, especialmente quando se trata de reprodução de histórias aprendidas a partir de texto escrito, como é o caso de, por exemplo, Chapeuzinho Vermelho.

De posse das entrevistas, o primeiro passo, portanto, foi fazer um levantamento de todos os $\mathrm{SNs}$ plurais, relacionando-os aos seus devidos contextos de ocorrência. Posteriormente, procedendo-se à audição das gravações, eles foram classificados em padrão e não-padrão. Alguns $\mathrm{SNs}$ foram submetidos a uma análise acústica no programa WINCECIL, para que pudéssemos verificar a acuidade de algumas transcrições. Além da caracterização da distribuição geral de SNs por entrevista/por idade, procedeu-se a um detalhamento analítico de SNs contendo numerais e possessivos, bem como de algumas ocorrências de SNs complexos.

\section{Resultados e Discussão}

Em virtude de serem poucos os dados disponíveis, a nossa análise quantitativa se restringirá a percentuais, uma vez que não seria seguro aplicar métodos mais sofisticados. Nosso objetivo é discutir algumas propostas de análise, lançar algumas hipóteses explicativas e tentar relacionar a aplicação da marca formal de plural com a alfabetização. 
Antes de passarmos à análise propriamente dita, apresentamos o quadro com a distribuição de SNs plurais coletados em cada entrevista.

QUADRO 1 - Número de SNs plurais por entrevista na fala de uma criança dos 4 aos 8 anos de idade

\begin{tabular}{|c|c|}
\hline Entrevista / idade & Total de SNs \\
$4 ; 03.07$ & 0 \\
\hline $4 ; 07.17$ & 1 \\
\hline $4 ; 09.19$ & 0 \\
\hline $5 ; 02.02$ & 5 \\
\hline $5 ; 03.00$ & 6 \\
\hline $5 ; 05.15$ & 0 \\
\hline $5 ; 08.01$ & 1 \\
\hline $5 ; 09.29$ & 4 \\
\hline $6 ; 03.05$ & 8 \\
\hline $6 ; 05.15$ & 5 \\
\hline $6 ; 07.16$ & 2 \\
\hline $6 ; 09.10$ & 11 \\
\hline $7 ; 01.27$ & 5 \\
\hline $7 ; 04.13$ & 1 \\
\hline $7 ; 07.16$ & 16 \\
\hline $7 ; 10.22$ & 34 \\
\hline $8 ; 01.15$ & 20 \\
\hline $8 ; 05.01$ & 7 \\
\hline TOTAL & $\mathbf{1 2 6}$ SNs \\
\hline
\end{tabular}

Como podemos perceber, o número de SNs produzidos por entrevista é bastante baixo: com exceção das entrevistas que correspondem às idades de 6;09.10, 7;07.16, 7;10.22 e 8;01.15, sempre temos menos do que $10 \mathrm{SNs}$ por entrevista.

Feito o primeiro levantamento, o próximo passo foi separar os SNs padrões dos não-padrões. $\mathrm{Na}$ tabela 1 , temos o número de SNs 
plurais padrões sobre o total de SNs plurais coletados por entrevista e a percentagem relativa em cada caso.

TABELA 1 - Número e percentual de SNs padrões por entrevista na fala de uma criança dos 4 aos 8 anos de idade

\begin{tabular}{|c|c|c|}
\hline $\begin{array}{c}\text { Entrevista (idade) } \\
4 ; 07.17\end{array}$ & SNs padrões / total de SNs \\
\hline $5 ; 02.02$ & $0 / 1$ & 0 \\
\hline $5 ; 03.00$ & $0 / 5$ & 0 \\
\hline $5 ; 08.01$ & $0 / 6$ & 0 \\
\hline $5 ; 09.29$ & $0 / 1$ & 0 \\
\hline $6 ; 03.05$ & $4 / 4$ & 100 \\
\hline $6 ; 05.15$ & $3 / 8$ & 37,5 \\
\hline $6 ; 07.16$ & $2 / 5$ & 40 \\
\hline $6 ; 09.10$ & $0 / 2$ & 0 \\
\hline $7 ; 01.27$ & $4 / 11$ & 36,36 \\
\hline $7 ; 04.13$ & $2 / 5$ & 40 \\
\hline $7 ; 07.16$ & $0 / 1$ & 0 \\
\hline $7 ; 10.22$ & $6 / 16$ & 37,5 \\
\hline $8 ; 01.15$ & $22 / 34$ & 64,70 \\
\hline $8 ; 05.01$ & $5 / 20$ & 25 \\
\hline TOTAL & $2 / 7$ & 28,57 \\
\hline & $50 / 126$ & 39,68 \\
\hline
\end{tabular}

De um modo geral, podemos observar, na tabela 1, que não há produção de SNs plurais padrões nas entrevistas iniciais, aparecendo somente a partir dos 5;09. Essa tendência revela uso preferencial da regra variável de marcação do plural própria da língua falada, como mostram os exemplos a seguir.

com meus coleguinha ${ }^{10}$ (relato pessoal) $(4 ; 07.17)$

um lago cheio de patinho (relato pessoal) (5;02.02)

dez balão (relato pessoal) (5;02.02) 
Como se observa, no primeiro caso, o plural é marcado apenas no possessivo. No segundo e terceiro casos, não há marca formal de plural. De acordo com o que vimos nos trabalhos revisados por nós, esses SNs assemelham-se aos produzidos pelo adulto.

Devemos lembrar, contudo, que as entrevistas não foram planejadas para testar uso do plural, como no trabalho de Lamprecht (1997). Os dados da Tabela 1, portanto, devem ser vistos com cautela. A não ocorrência de formas padrão nessas primeiras entrevistas não pode ser interpretada como indicativo de que a criança não adquiriu a regra de concordância. É mais provável que ela opere, em maior ou menor grau, com os dois sistemas que supomos presentes no input: o da língua falada e o padrão. Uma investigação da emergência do plural, que inicie com coleta precoce, antes mesmo dos 2 anos, e a testagem sistemática do uso do plural provavelmente forneceriam uma base mais adequada para a discussão dessas questões.

Verificamos, também, que os SNs padrões ficam entre $25 \%$ e 40\%, com duas exceções, aos 5;09.29 - quando são 100\% dos casos - e aos 7;10.22 - quando são 64,70\% dos casos.

Vejamos mais de perto esses dois casos de grande uso padrão. A entrevista que corresponde à idade dos 5;09.29, como dissemos, apresenta $100 \%$ de plurais padrão (4 ocorrências). Todavia, o fato de terem sido produzidos em um discurso baseado em um texto escrito (Os Três Porquinhos) provavelmente explica esse resultado discrepante. A outra exceção refere-se à entrevista que corresponde à idade dos 7;10.22. Esses SNs foram produzidos em situação de relato pessoal, mas nesse caso, a criança estava contando sobre um teatro de que ela participou na escola. Há, ainda, o fato de que esse teatro foi uma adaptação de um livro infantil e foi ela quem fez essa adaptação. Trata-se, portanto, de uma fala que toma por base, em certa medida, um texto escrito.

Esses casos discrepantes apontam para a importância do contexto. Assim, para melhor caracterizar o uso de SNs padrões e não-padrões, apresentamos, na tabela 2, sua distribuição em rela- 
ção aos dois tipos de contextos discursivos: relato pessoal e narrativa oral de historinha.

TABELA 2 - Número e percentual de SNs plurais padrões na fala de uma criança dos 4 aos 8 anos de idade, considerando o contexto em que foram produridos

\begin{tabular}{|l|l|l|}
\hline & Padrão & \\
& N/Total & $\%$ \\
relato pessoal & $29 / 84$ & 34 \\
\hline contando historinha & $21 / 42$ & 50 \\
\hline Total & $50 / 126$ & 39 \\
\hline
\end{tabular}

Como se observa, há maior número de SNs padrões no contexto de contar historinhas $(50 \%)$, sugerindo uma influência do texto escrito padrão que, em certa medida, pode ter sido memorizado pela criança. No relato pessoal, em que há apenas 34\% de SNs padrões, o discurso é mais espontâneo, em princípio, a menos que sejam casos em que o falante se reporte a textos escritos ou eventos de fala em que se tivesse usado linguagem formal, mais próxima do padrão. Nos dados de Carmela isso ocorre, como já mencionado, em relação à entrevista feita aos 7;10.22. De modo geral, portanto, o contexto discursivo parece influenciar no uso da regra padrão. Não se pode esquecer, também, que esta criança freqüenta escola e se alfabetiza no curso da coleta de dados, o que também poderia determinar um incremento no uso da regra padrão. Contudo, a distribuição por entrevista, apresentada na tabela 1, mostra não um incremento progressivo, e sim uma oscilação que não sustenta essa hipótese e sugere a necessidade de análises mais refinadas.

Para tentar caracterizar melhor os dados, passaremos a discutir alguns SNs que consideramos interessante explorar, sempre levando em conta os contextos em que eles foram produzidos.

Os SNs que gostaríamos de comentar são os seguintes: 
1) os pés todo embarrado (5;02.02) (relato pessoal)

2) um monte de coisa $(5 ; 03.00)$ (relato pessoal)

3) os três porquinhos (5;09.29)

4) umas ferinha [feira] (6;09.10) (relato pessoal)

5) uns hambúrgueri (7;01.27) (relato pessoal)

6) trinta reais $(7 ; 07.16)$ (relato pessoal)

7) milhares de borracha $(8 ; 01.15)$ (relato pessoal)

No primeiro SN (os pés todo embarrado), há marca formal de plural apenas nos dois primeiros elementos, e a estrutura é complexa. O item todo modifica embarrado e parece quebrar a seqüência, ou a coesão, segundo Sherre (1996:100), o que justificaria a ausência de marca no último elemento. Em Pontes ${ }^{11}$ (1978:152), vimos que todo pode se movimentar para várias posições da oração. Contudo, no SN em questão, tal mobilidade não é possível. Nesse caso, ele pode ser substituído por tudo, tal como usado na fala popular.

Os pés tudo embarrado.

Outra possível substituição seria:

Os pés totalmente embarrados.

Porém, a permutação não poderia ser feita pelo operador todos, pois o significado que o contexto permite inferir seria alterado:

Os pés todos embarrados./ Todos os pés embarrados./ *Os pés embarrados todos.

A alteração se daria pelo fato de que todo, tudo, totalmente modifica o particípio embarrado. Nesse caso, tal SN significa: Os pés dela totalmente, completamente embarrados. Ao passo que a substituição por todos 
*Os pés todos embarrados./ Todos os pés embarrados.

modificaria o núcleo pés, ou seja, não se trataria da quantidade de barro nos pés dela, mas sim, o número de pés embarrados presentes na situação. Portanto, no SN produzido por Carmela - Os pés todo embarrado- o quantificador é invariável, comparável a tudo, descartando-se a possibilidade, nesse caso, de queda de -s. Por isso, talvez não ocorra o acionamento da regra de marcação depois do referido itemOs pés todo embarradoo.

O SN 2 (um monte de coisa) foi encontrado mais de uma vez e sempre sem marca de plural. Para analisar esse SN, buscamos a dissertação de Simões (1992), que trata da Aquisição da Distinção Semântica entre Nominais Contáveis e Não-Contáveis em Lingua Portuguesa. Nesse trabalho, a autora mostra, entre outras coisas, que a flexão do plural está relacionada à noção de nominais contáveis e não-contáveis (1992:89). Um exemplo de não-contável é o termo monte, que aparece no SN produzido pela Carmela. Nesse SN não há a individuação das coisas do monte e isso levaria ao não acionamento do plural no segmento seguinte de coisa. Ou seja, monte, é um quantificador massivo; portanto, a não marcação deve-se à não identificação de elementos contáveis necessários para o reconhecimento do plural. Nessa situação, podemos enquadrar outras ocorrências, como um pacote de borracha (8;01.15) e uma pasta de foto $(8 ; 01.15)$. Somando-se a esses argumentos, temos a preposição de sugerindo fronteira entre constituintes sintáticos, além de ter esta preposição valor partitivo, o que desfavorece, mesmo na gramática do adulto, a ocorrência do plural.

No caso 3 (os três porquinhos) temos algo muito significativo, pois é o primeiro SN com marca formal de plural nos elementos flexionáveis e repetido quatro vezes na entrevista. É interessante salientar, mais uma vez, o provável papel que o contato com o texto escrito 
desempenha na aplicação da regra de concordância de número, já que na escrita os determinantes pluralizados vêm separados por espaços em branco do determinado, facilitando, talvez, a internalização dos morfemas de plural. Outra hipótese é que Os Três Porquinhos é uma forma aprendida de memória, e a criança já deve ter escutado essa historinha muitas vezes. Isso, certamente, favorece a retenção do $-s$ na terceira posição, depois do numeral. Há, também, o caso do plural metafônico porco / pórcos, possivelmente favorecendo na aplicação da regra, pois de acordo com o que se evidencia nos dados e conforme literatura já vista, itens diminutivos e numerais, conforme veremos adiante, desfavorecem marcas de plural. Porém, essa constatação parece não se aplicar a SNs aprendidos de memória, como é o caso de Os Três Porquinhos.

Em 4 (umas ferinha), reconhecemos a tendência não verificada no caso acima. Esse vocábulo, assim como outros encontrados (os bonequinho, esses pãozinho) reiteram a proposta apresentada por Scherre (1996:90) na qual os itens diminutivos realmente desfavorecem a concordância de número da língua padrão. Soma-se a essa constatação a situação de fala espontânea.

Em 5 (uns hamburgueri), o SN não foi considerado padrão, mas o fato de a criança não ter optado pela forma singular (bambuirguer), optando por uma forma muito próxima da padrão, em que houve a inserção da vogal final esperada, faz-nos pensar que talvez pudesse ser o caso de um apagamento de $-s$. Se assim pensarmos, temos que admitir que em algum momento da aquisição dessa criança houve o plural padrão, para que esse pudesse ser apagado. Todavia, não podemos descartar a possibilidade de estar havendo nesse caso apenas uma epêntese, sem nunca ter existido uma forma com $-s$. Obviamente, nossa análise não foi planejada para investigar especificamente essa regra, mas achamos importante o registro desse caso, pois sugere futuras análises. 
A ocorrência do SN 6 (trinta reais) em sua forma padrão não era esperada por nós, pois, conforme o que Scherre (1996) apresenta para SNs com numerais e de acordo com outros casos levantados por nós, o esperado seria o SN não marcado para plural trinta real. Entretanto, o contexto em que foi produzido tal sintagma nos faz pensar que talvez se trate de um discurso reproduzido do pai da informante, manifestando-se em relação ao dinheiro gasto por ela. Acreditamos ser possível que seja esse o fator determinante, pois conforme a análise dos numerais que faremos a seguir, eles parecem não favorecer a marcação formal de plural.

O caso 7 (milhares de borracha) tem o vocábulo milhares como desfavorecedor da aplicação da regra. Além disso, esses casos, por conterem a preposição de, seriam, provavelmente, menos coesivos, segundo o conceito de coesão sintagmática apresentado por Scherre (1996:100), o que leva a supor a possibilidade de análise alternativa, em que o SN só contém N (borracha). De qualquer forma, esse parece ser um caso que desfavorece a aplicação da regra padrão.

Diante do registro, na literatura, de que os numerais desfavorecem a marca de plural, apresentamos, na tabela 3, uma análise desses casos na fala da Carmela.

TABELA 3 - Número e percentual de SNs padrões com numerais, especificados por contexto na fala de uma criança de 4 a 8 anos de idade

\begin{tabular}{|l|l|l|}
\hline & SNs padrões & \\
& N / Total & $\%$ \\
contando historinha & $5 / 6$ & 83 \\
\hline relato pessoal & $4 / 10$ & 40 \\
\hline TOTAL & $9 / 16$ & 56 \\
\hline
\end{tabular}

De um modo geral, o resultado final parece não confirmar o esperado. Em outras palavras, tínhamos como hipótese que, com nu- 
merais, a nossa informante produziria mais SNs não-padrões do que SNs padrões; os resultados, contudo, mostram o contrário: são $56 \%$ de SNs padrões com numerais, índice bem maior do que os $39,68 \%$ de SNs padrões obtidos no conjunto dos dados. Entretanto, consideramos que a ocorrência de uma forma ou de outra não depende apenas de fatores estruturais e, nesse caso, acreditamos que o contexto tenha influenciado, principalmente, quanto a trinta reais e três porquinhos, como já discutido. Assim, destacando que o número de ocorrências não é muito expressivo e que fatores como o contexto podem estar atuando, nossos dados não parecem suficientes para negar a tendência de os numerais desfavorecerem a concordância de número na fala.

Um outro ponto que chamou nossa atenção, nos dados, diz respeito aos possessivos. Constatamos, na análise acústica, que estruturas do tipo artigo + possessivo apresentavam a marca de plural no possessivo e não no artigo.

\section{aminhas daminhas}

Tal constatação nos faz perguntar por que o -s não está no artigo, que é a posição de determinante e a, sabidamente, mais favorecida para retenção do plural?

Conforme já propusemos no início deste trabalho, temos uma hipótese, que encontra eco no trabalho da Rosa V. Mattos e Silva, de que nesses casos pode estar havendo um processo assimilatório entre o artigo e o possessivo. Assim, o que estaria acontecendo não é uma marcação na segunda posição, pois a marca permaneceria na primeira, ainda que assimilada, se considerássemos tal hipótese.

foram aminhas prima (7;1.27) (relato pessoal)

é que fui no Mc Donald's, dai aminhas primas que moram em Curitiba $(7 ; 1.27)$ (relato pessoal). 
essas [borrachas ganhei], daminhas primas emprestadas (8;1.15) (relato pessoal)

Diante disso, fizemos um levantamento das ocorrências de possessivos com e sem artigo, no plural e no singular, buscando alguma literatura sobre o assunto. Os dados levantados encontram-se na tabela 4.

TABELA 4 - Total de possessivos antecedidos por artigo ou não na fala de uma criança dos 4 aos 8 anos de idade

\begin{tabular}{|l|c|c|c|}
\hline & SNs singulares & SNs plurais & Total \\
Possessivo $+\mathrm{N}$ & 27 & 06 & 33 \\
\hline artigo + posses. $+\mathrm{N}$ & 69 & 12 & 81 \\
\hline prep. + art. + posses. $+\mathrm{N}$ & 31 & 01 & 32 \\
\hline prep. + posses. $+\mathrm{N}$ & 0 & 0 & 0 \\
\hline
\end{tabular}

À primeira vista, a presença do artigo antes do possessivo parece bastante regular, conforme os nossos resultados. No singular são 100 ocorrências (78\%) de possessivos precedidos de artigo contra 27 sem artigo. No plural, são 13 ocorrências com artigo (68,42\%) contra 6 sem artigo. Ao separarmos os SNs plurais em padrão e não-padrão, obtivemos os seguintes resultados:

1) Para as formas no plural de possessivo $+N-$ de um total de 6 ocorrências, 3 são plurais padrões e 3, plurais não-padrões.

\section{PADRÃO}

meus pais $(4,09.19)$ (relato pessoal) meus tios (8,01.05) (relato pessoal) minhas tias (8;01.05) (relato pessoal)

\section{NÃO-PADRÃO}

minhas colega $(5,03.00)$ (relato pessoal) seus brinquedo $(7 ; 10.22)$ (relato pessoal) colegas minha (8;01.05) (relato pessoal)

2) Para as formas no plural de artigo + possessivo $+N-$ de um total de 12 SNs, 6 são padrões e 6, não-padrões. 


\section{PADRÃO}

as minhas duas primas (7;07.16) (relato pessoal)

as minhas duas primas (7;07.16) (relato pessoal)

os seus brinquedos $(7 ; 10.22)$ (contando historinha)

as minhas primas (8;01.15) (relato pessoal)

as minhas duas primas (8;01.05) (relato pessoal)

as minhas primas (8;01.05) (relato pessoal)

\section{NÃO-PADRÃO}

com o meus coleguinha $(4 ; 07.17)$

a minhas amiguinha $(4 ; 07.17)$ (relato pessoal)

a minhas primas $(7 ; 01.27)$ (relato pessoal)

a minhas colega $(7 ; 01.27)$ (relato pessoal)

as minhas prima $(7 ; 07.16)$ (relato pessoal)

as minhas prima $(7 ; 07.16)$ (relato pessoal)

3) Para a forma plural de preposição + artigo $+N-$ temos 1 única ocorrência, que é não-padrão:

daminhas prima (8;01.15) (relato pessoal)

Sobre esse assunto, Giselle M. de Oliveira e Silva (1996:125) afirma que o uso do artigo diante de possessivos tem a ver com o maior ou menor grau de especificidade da referência. Assim, os exemplos da autora, obtidos através de corpus oral, explicitam a relação:

meu livro - é não especificado e inibe o artigo.

$\boldsymbol{o}$ meu livro de francês - é especificado e propicia o artigo.

Os resultados obtidos mostram (Silva, 1996:125) uma probabilidade de 0,42 para a variável não-especificado (resultado desfavorável) e 0,58 para a variável especificado (resultado favorável ao uso do artigo antes do possessivo).

Uma observação se faz necessária quando se trata de referência a 
parentesco. Nesse caso, o possuído pode ser claramente específico (meu pai, minha mãe), tornando o artigo redundante. Com relação a essa constatação é curioso observarmos que nos nossos dados o uso de artigo antes de possessivo referente a parentesco é bastante intenso, mas trata-se de referência a primas, tios, etc. Sobre as crianças, Oliveira e Silva (1996:141) ainda acrescenta que elas acreditam que o ouvinte compartilha do mesmo conhecimento que elas. Então, as crianças não se empenham em definir a entidade, mas tendem a se referir a ela como se o ouvinte a conhecesse. Portanto, são comuns enunciados como os que a autora apresenta:

Eu já disse pra ela, a Vânia, disse já pra ela que o Pica-pau...

Ainda que essas observações pareçam importantes, não empreendemos uma análise semântica da referência em nossos dados, por limitações da própria proposta deste trabalho. Fica registrada, então, a sugestão para que tal análise seja feita.

Outra constatação de Oliveira e Silva (1996:126) é que os artigos ocorrem menos diante de possessivos no plural. As probabilidades da autora são de 0,63 para singular e 0,37 para plural. Isso nós também verificamos em nossos dados, se compararmos singular e plural dentro de cada categoria: sem artigo, temos 27 casos no singular contra 6 no plural, ou seja, 4 vezes mais; com artigo, temos 100 casos no singular, contra 13 no plural, ou seja, 7 vezes mais.

Enfim, diante dessa tendência tão robusta de uso de artigo diante de possessivo, tanto no singular quanto no plural, a nossa hipótese é de que, nos $\mathrm{SNs}$ plurais, o artigo perca o $-s$ num processo de assimilação e aglutinação com o possessivo, semelhante ao exemplo de tod'os ${ }^{12}$.

Aqui concluímos nossa análise, reafirmando, contudo, a necessidade de um estudo mais aprofundado, com dados mais adequados e em maior quantidade. De qualquer modo o exame dos dados de Carmela mostra muitos pontos de contato com o que a literatura descre- 
ve para os adultos e aponta na mesma direção do trabalho de Lamprecht (1997) sobre a importância do input. Qualifica-se, contudo, essa constatação, mostrando que a criança em questão parece operar com dois sistemas, segundo os contextos discursivos, ora empregando a regra padrão, ora a regra variável.

\section{Considerações finais}

O nosso trabalho tem como característica principal mais do que fornecer respostas, levantar questões. Desse modo, nesse momento final, faremos uma breve retomada do que foi visto, juntamente com as hipóteses que nos acompanharam ao longo deste percurso.

$\mathrm{Na}$ primeira parte deste trabalho, foram discutidos estudos que focalizam a concordância de número na fala dos adultos, afirmando que a marcação de plural é uma regra variável. Nesse sentido, muitas propostas são apresentadas pelos autores, algumas delas questionadas por nós. Entre essas propostas, estão as de Scherre (1996), que considera, basicamente, a influência de duas variáveis lingüísticas na aplicação da regra: 1) relação entre elementos nucleares e não-nucleares e posição dos elementos nucleares no SN; 2) marcas precedentes em função da posição. A nossa posição é de que a categoria elementos não-nucleares precisa ser repensada com base em uma descrição estrutural mais acurada do SN. Levantamos esse questionamento, pois consideramos que alguns elementos aí incluídos talvez não pertençam à estrutura do $\mathrm{SN}(\operatorname{det}+\mathrm{N})$. É o caso do operador todos, por exemplo, que é tratado como determinante, mas que apresenta muitas particularidades combinatórias que o distinguem dos demais casos de determinantes. Para encontrarmos algum subsídio, buscamos na Teoria Gerativa e em Perini (1998) a descrição dos contextos que mostram esse comportamento sintático diferenciado. Há, também, a relação com o elemento tudo, muito difundido na fala popular. Essas possibilidades nos fazem pensar que algumas classes mereçam um tratamento à parte na análise da marcação de plural, em 
particular os numerais e, quem sabe, os quantificadores. Nesse sentido, pensamos que uma análise mais refinada dessas categorias possa esclarecer melhor quais são, de fato, os contextos favoráveis à regra variável de marcação do plural na língua falada. Em lugar de agrupar todos esses elementos como uma grande categoria, pensamos que seja necessário distinguir subgrupos em função das restrições sintáticas e de processos fonológicos e morfossintáticos envolvidos.

Não podemos ignorar, nesse sentido, o registro das ocorrências históricas que Mattos e Silva (1989) faz das formas combinadas que ocorriam no português arcaico. A nossa outra hipótese é de que o apagamento da marca formal de plural ocorra devido a um processo de assimilação, semelhante ao que aconteceu naquele período da língua portuguesa.

Temos também que pensar na relação que as primeiras posições do SN têm com a retenção do -s. Para essa questão, temos o texto da Koch, propondo uma hierarquia dentro do que se entende por determinante. Além disso, é preciso investigar em que medida isso poderia ter resultado dos contatos entre o português e as línguas indígenas e africanas no Brasil. Essa possibilidade tem sido discutida por autores como Baxter (1992) e, a nosso ver, merece ser considerada ao se repensar a questão da estrutura do SN e da marcação de plural.

Portanto, é nesse sentido que consideramos a análise de Scherre um tanto quanto genérica, pois caracterizar a aplicação da regra para o que está antes ou depois do núcleo parece mais esconder do que revelar. Nessa primeira parte, foram essas as bases e hipóteses levantadas.

$\mathrm{Na}$ segunda parte, focalizamos esse fenômeno na fala das crianças. Regina Lamprecht (1997) compara como se dá a aquisição da morfologia do plural entre crianças monolíngües em português e bilíngües falantes de português e alemão. A autora conclui que as bilíngües fazem mais uso da marcação formal de plural do que as monolíngües falantes de português. Ela atribui isso à necessidade que as bilíngües têm de prestar atenção ao final das palavras do 
alemão, fazendo com que acabem prestando mais atenção ao final das palavras em português. Lamprecht ainda salienta a importância do input, pois afirma que as monolíngües expostas à variante padrão usam mais a marcação formal. O mesmo ocorre para as bilíngües: devido à pouca exposição à língua, elas demoram mais a adquirir a morfologia do alemão, quando comparadas às monolíngües alemãs.

$\mathrm{Na}$ última seção, analisamos dados de uma criança entre os 4 e os 8 anos. Infelizmente, o corpus reduzido não nos possibilitou uma análise quantitativa mais refinada; optamos então, por discutir somente os totais e os percentuais correspondentes. Algumas conclusões são a seguir destacadas:

- o contato com o texto escrito parece estimular o uso de plurais padrões;

- os numerais e os quantificadores não tendem a acionar o uso da regra padrão, exceto quando relacionados a expressões aprendidas de memória (Os Três Porquinhos), ou a contextos que têm por base textos escritos;

- itens diminutivos desfavorecem a marcação de plural exceto, também, quando aprendidos de memória (Os Três Porquinhos).

O que observamos, portanto, é um comportamento semelhante ao dos adultos, pois estas mesmas considerações já foram feitas em relação à sua fala. Todavia, um questionamento proposto por nós na parte inicial do trabalho foi retomado em função dos nossos dados: como explicar ocorrências como: aminhas / omeus?

Levantamos a hipótese de tratar-se de processo fonológico de assimilação. Seria necessário verificar, contudo, se só atinge os casos em que o - s final de palavra é marca de plural (nesse caso não seria um processo tipicamente fonológico), ou se atinge, também, palavras terminadas em - s (simples, lápis, etc.). Há, portanto, neste e noutros aspectos, muito, ainda, a ser investigado. 
Por fim, parece importante mencionar um último ponto. A influência que a escola pode ter em favorecer o uso das formas padrões da língua não se delineou claramente neste trabalho. A fala da Carmela nos sugere que ela põe em prática dois tipos de gramática, e isso parece estar relacionado com os contextos discursivos. Assim, ainda que, nas interações, não houvesse formalidade, quando o seu discurso tinha por base um texto escrito, as formas padrões a ele pertinentes apareciam.

Por isso, a nosso ver, não deveria ser objetivo de nenhum professor de português fazer com que seus alunos não comam os $-\mathrm{s}$ finais das palavras quando falam, até porque os resultados seriam frustrantes. Então, ao invés das frustrações e da perda de tempo, o melhor seria empenhar-se em formar leitores. Estimulando-se leitura desde a mais tenra infância, há mais chances de acionarem as regras formais de marcação de plural quando forem necessárias, conforme os dados da Carmela indicam. $\mathrm{O}$ input, pois, parece ser um elemento chave.

Recebido em abril de 2002. Versão revisada aceita em junho de 2002.

\section{Referências bibliográficas}

BAXTER, Alan. A contribuição das comunidades afro-brasileiras isoladas para o debate sobre a crioulização prévia: um exemplo do Estado da Bahia. In: D’ANDRADE; KIHM (Org.). Actas do colóquio sobre "crioulos de base lexical portuguesa". Lisboa, Colibri, 1992. p.7-35.

CÂMARA Jr., Joaquim Mattoso. História e estrutura da língua portuguesa. 2a. Ed., Rio de Janeiro, Padrão, 1976.

GUIMARÃES, Ana Maria de Mattos. Relatório: Projeto Desenvolvimento da Linguagem da Criança em Fase de Letramento. Porto Alegre. [1995]. Texto não publicado.

KOCH, Ingedore. Lingüística Aplicada ao Português: sintaxe. São Paulo, Cortez, 1983.

LAMPRECHT, Regina Ritter. Aquisição da morfologia do plural por 
crianças bilíngües Português - Alemão. In: I ENCONTRO DO CELSUL, 1997, Florianópolis, Anais. Florianópolis, UFSC, 1997. v.1. p.107-117.

MATTOOS E SILVA, Rosa Virgínia. Estruturas Trecentistas Elementos para uma gramática do Português Arcaico. Lisboa: Imprensa Nacional - Casa da Moeda, 1989.

PERINI, Mário A. Gramática descritiva do português. $3^{a}$. ed., São Paulo, Ática, 1988.

PONTES, Eunice. Os determinantes em português. Tempo Brasileiro, Rio de Janeiro, n. 53/54, 1978. p. 145-167.

SCHERRE, Maria Pereira. Sobre a influência de três variáveis relacionadas na concordância nominal em português. In: SCHERRE; SILVA (Org.). Padrões Sociolingüísticos : análise de fenômenos variáveis do português falado na cidade do Rio de Janeiro. Rio de Janeiro, Tempo Brasileiro, 1996. p. 85-117.

SCHERRE, Maria Pereira. Sobre a influência de variáveis sociais na concordância nominal em português. In: SCHERRE; SILVA (Org.). Padrões Sociolingüísticos : análise de fenômenos variáveis do português falado na cidade do Rio de Janeiro. Rio de Janeiro, Tempo Brasileiro, 1996. p. 239-64.

SILVA, Giselle Machline de Oliveira e. Realização facultativa do artigo definido diante de possessivo e de patronímico. In: SCHERRE; SILVA (Org.). Padrões Sociolingüísticos : análise de fenômenos variáveis do português falado na cidade do Rio de Janeiro. Rio de Janeiro, Tempo Brasileiro, 1996. p. 119-45.

SIMÕES, Luciene Juliano. Aquisição da distinção semântica entre nominais contáveis e não-contáveis em língua portuguesa, PUCRS, 1992. Dissertação (Mestrado) - Pontifícia Universidade Católica do Rio Grande do Sul. Curso de Pós Graduação em Letras.

1 Agradecemos ao projeto DELICRI pelos dados fornecidos, bem como à professora Luciene Simões pelos comentários que ajudaram a compor este trabalho. Do mesmo modo, somos gratas aos pareceris- 
tas anônimos.

${ }^{2}$ Empregamos aqui, por conveniência, o acento gráfico no lugar da representação fonológica para indicar abertura de vogal.

${ }^{3}$ As palavras marcar/marcada estão sendo utilizadas para se referir ao acréscimo do morfema $-\mathrm{s}$ ao longo dos elementos dos SNs analisados.

${ }^{4}$ Caberia discutir, também, a existência, pelo menos na linguagem popular e rural, de um quantificador invariável tudo: Tudo os menino / os menino tudo. Sua inclusão na estrutura linear do SN - como elemento não-nuclear - seria inadequada (não haveria variação entre ser ou não ser marcado quanto ao plural) no âmbito da análise de regra variável.

${ }^{5} \mathrm{O}$ mesmo que plural metafônico, termo por nós utilizado.

"Os termos "acertos" e "erros" são usados pela pesquisadora e referem-se às formas desviantes do padrão gramatical das línguas em questão.

${ }^{7}$ A autora não esclarece como isso foi determinado.

${ }^{8}$ Essa comparação toma por base resultados de pesquisas de aquisição realizadas na Alemanha.

${ }^{9}$ Leia-se 8 anos, 5 meses e 1 dia.

${ }^{10}$ De acordo com um parecerista anônimo, seria necessário apresentar a transcrição fonética dos dados para evidenciar os condicionamentos fonéticos que favoreceriam a realização da marcação morfológica de plural. Entretanto, seguimos a mesma orientação dos estudos em variação utilizados neste artigo, os quais também não transcrevem foneticamente os dados. Além disso, não focalizamos, neste trabalho, as possíveis motivações de desenvolvimento fonológico para tal fenômeno, o que evidentemente não quer dizer que não haja tais motivações.

${ }^{11}$ Este item já foi discutido na seção 3 deste trabalho.

12 A discussão sobre esse item está na seção 3 deste trabalho. 